\title{
Using bacterial inclusion bodies to screen for amyloid aggregation inhibitors
}

\author{
Anna Villar-Piqué ${ }^{1,2+}$, Alba Espargaró ${ }^{2 \dagger}$, Raimon Sabaté 2,3 , Natalia SdeGroot ${ }^{2,4}$ and Salvador Ventura ${ }^{1,2^{*}}$
}

\begin{abstract}
Background: The amyloid- $\beta$ peptide $(A \beta 42)$ is the main component of the inter-neuronal amyloid plaques characteristic of Alzheimer's disease (AD). The mechanism by which A 342 and other amyloid peptides assemble into insoluble neurotoxic deposits is still not completely understood and multiple factors have been reported to trigger their formation. In particular, the presence of endogenous metal ions has been linked to the pathogenesis of $A D$ and other neurodegenerative disorders.

Results: Here we describe a rapid and high-throughput screening method to identify molecules able to modulate amyloid aggregation. The approach exploits the inclusion bodies (IBs) formed by A 342 when expressed in bacteria. We have shown previously that these aggregates retain amyloid structural and functional properties. In the present work, we demonstrate that their in vitro refolding is selectively sensitive to the presence of aggregation-promoting metal ions, allowing the detection of inhibitors of metal-promoted amyloid aggregation with potential therapeutic interest.
\end{abstract}

Conclusions: Because IBs can be produced at high levels and easily purified, the method overcomes one of the main limitations in screens to detect amyloid modulators: the use of expensive and usually highly insoluble synthetic peptides.

Keywords: Amyloids, Inclusion bodies, Protein folding, Protein aggregation, Metals, Alzheimer

\section{Background}

In the last few years, protein aggregation has emerged from a neglected area of protein chemistry as a transcendental issue in biological and medical sciences, mainly because the deposition of proteins into insoluble amyloid fibrils is being found behind an increasing number of human diseases such as Alzheimer's disease (AD) or type II diabetes [1-4]. Therefore, there is an increasing interest in developing methods to identify molecules that trigger the aggregation of these proteins inside the organism as well as to discover chemical compounds that can interfere with these pathways, having thus therapeutic potential [5-7].

The pathological hallmark of $\mathrm{AD}$ is brain deposition of amyloid plaques composed predominantly by the A 342 peptide isoform [8-10]. The origin of these insoluble

\footnotetext{
* Correspondence: salvador.ventura@uab.es

${ }^{\dagger}$ Equal contributors

'Departament de Bioquímica i Biologia Molecular, Facultat de Ciències, Universitat Autònoma de Barcelona, E-08193, Bellaterra, Spain ${ }^{2}$ Institut de Biotecnologia i de Biomedicina, Universitat Autònoma de Barcelona, E-08193, Bellaterra, Spain

Full list of author information is available at the end of the article
}

extracellular neurotoxic deposits is still not completely clear, and multiple factors such as $\mathrm{pH}$, peptide concentration, oxidative stress and metal ions have been reported to trigger their formation [11,12]. Here we present a fast, cost-effective high-throughput approach to study conditions and molecules that affect A 442 aggregation. The assay is based on the use of the inclusion bodies (IBs) formed by an A $\beta 42$-GFP fusion protein in bacteria. IBs formation has long been regarded as an unspecific process relaying on the establishment of hydrophobic contacts $[13,14]$. However, there are now strong evidences demonstrating that bacterial IBs formation shares a number of common features with the formation of the highly ordered and pathogenic amyloid fibrils linked to human diseases [15-18]. Therefore, IBs have become an attractive model to study protein aggregation and their consequences in simple but biologically relevant environments [19-21]. IBs are formed inside the cell when the folding of proteins into native conformations is competed by a faster establishment of anomalous intermolecular interactions that leads to the formation of insoluble aggregates [22]. In the present work,

\section{Biomed Central}


we exploit this kinetic competition in vitro to screen for compounds that can modulate protein aggregation. As a proof of principle, we demonstrate the ability of the approach to detect the effect of metal ions on $A \beta 42$ aggregation as well as to identify compounds that block this metal-induced reaction.

\section{Results and Discussion}

Refolding $A \beta 42-G F P$ IBs is sequence specific

We have previously shown that the IBs formed by $A \beta 42$ display amyloid-like properties whether the peptide is expressed alone [23] or fused to fluorescent proteins
$[16,24]$. We have constructed a set of 20 different $A \beta 42-$ GFP variants, which differ only in a single residue in the peptide's central hydrophobic region [25]. All these proteins are expressed at similar levels in E. coli and form insoluble IBs [25]. Nevertheless, the fraction of active GFP in those aggregates is significantly different (Figure $\mathbf{1}$ ). The IBs fluorescence correlates with the aggregation propensity of the specific $A \beta 42$ mutant [26]. This correlation is the result of a kinetic competition between the folding of the GFP domain and the aggregation of the fusion protein, which is driven by the $A \beta 42$ moiety. Therefore, the slower the fusion protein aggregates, the higher the IB fluorescence

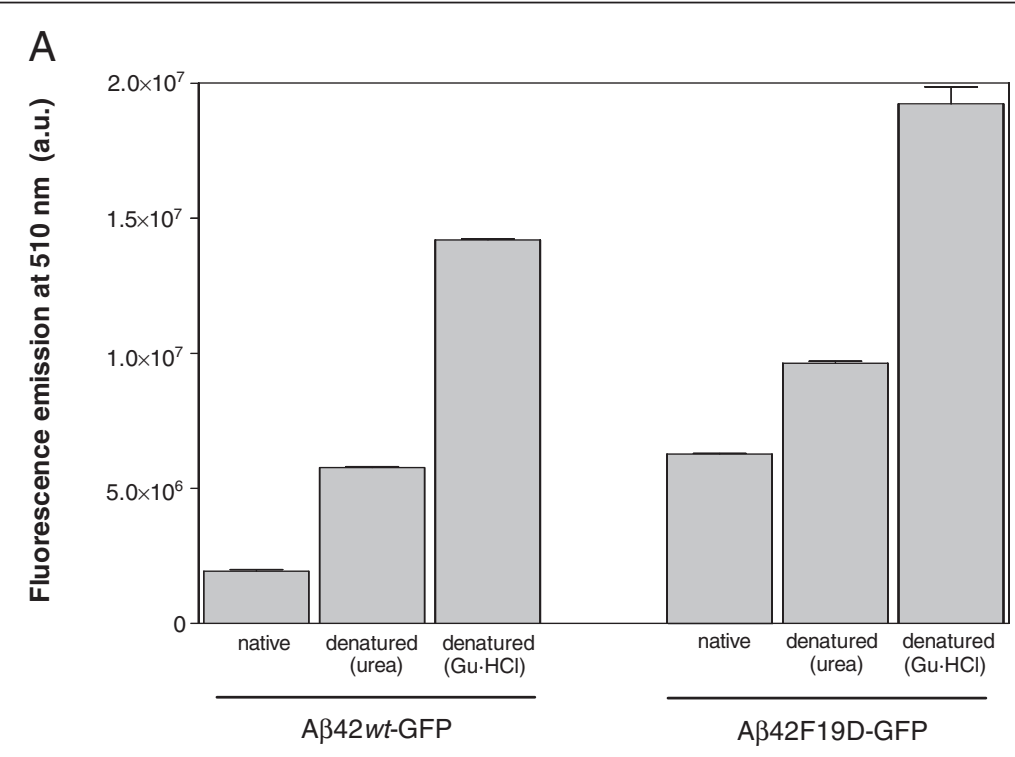

B

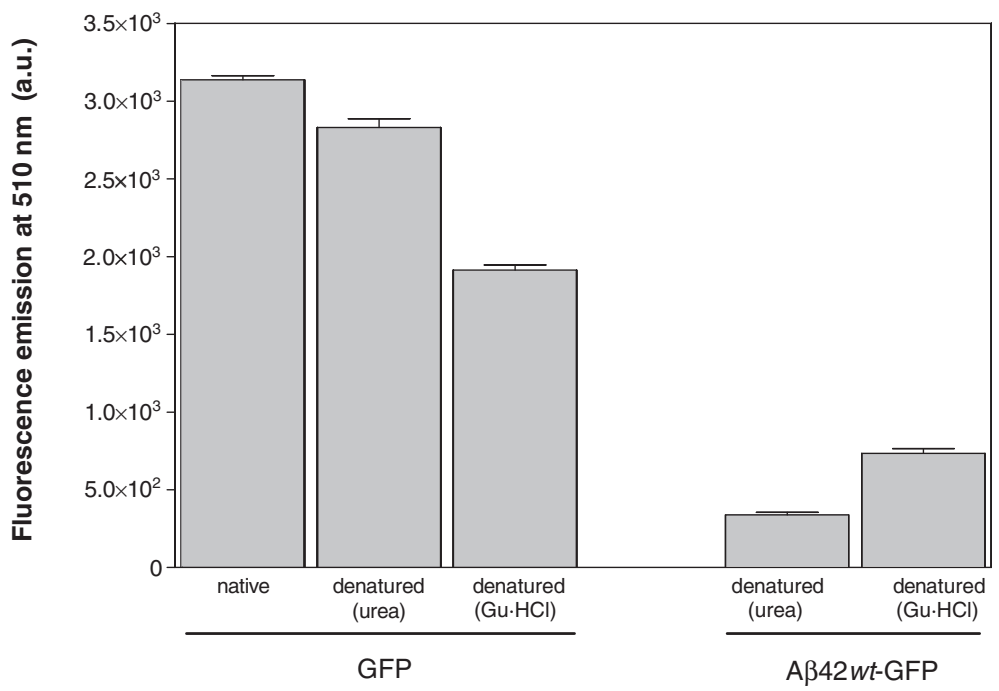

Figure 1 Fluorescence recovery after denaturation. (A) Purified IBs were incubated in PBS in the absence (native) and presence of $8 \mathrm{M}$ Gu.HCl or $10 \mathrm{M}$ urea for $4 \mathrm{~h}$ and diluted 100-fold in PBS. (B) Purified untagged GFP (left) and IBs (right) were incubated in PBS in the absence (native) and presence of $8 \mathrm{M} \mathrm{Gu} \cdot \mathrm{HCl}$ or $10 \mathrm{M}$ urea for $4 \mathrm{~h}$ and diluted 100-fold in PBS. In all cases, after incubation for $16 \mathrm{~h}$ fluorescence was recorded at $510 \mathrm{~nm}$. 
emission is and vice versa. In this way, IBs fluorescence reports on intracellular aggregation kinetics [22,26,27].

We wondered if the kinetic competition between GFP folding and $A \beta 42$ aggregation can be reproduced in vitro. To this aim we used the IBs formed by the wild-type peptide fusion (A $\beta 42 w t$-GFP) and the F19D mutant (Aß42F19D-GFP), which display the highest and lowest aggregation propensities in our library, respectively [22]. Purified IBs were denatured to remove the polypeptide contacts supporting the aggregate structure. This provides unfolded and isolated species for the subsequent in vitro refolding step and guarantees that all inter- or intra-molecular contacts are established de novo as it happens after protein synthesis in the cell. IBs were chemically denatured using two chaotropic agents, $10 \mathrm{M}$ urea and $8 \mathrm{M} \mathrm{Gu} \cdot \mathrm{HCl}$. Each unfolded A $\beta 42-\mathrm{GFP}$ fusion was diluted in refolding buffer and the amount of recovered active GFP monitored using fluorescence spectroscopy (see Methods). The same conditions were used to unfold and refold equimolar concentrations of native untagged GFP. As it can be seen in Figure 1A, independently of the IBs peptide variant, the level of recovered GFP activity was higher when $\mathrm{Gu} \cdot \mathrm{HCl}$ was used as denaturant. This is in contrast with the results
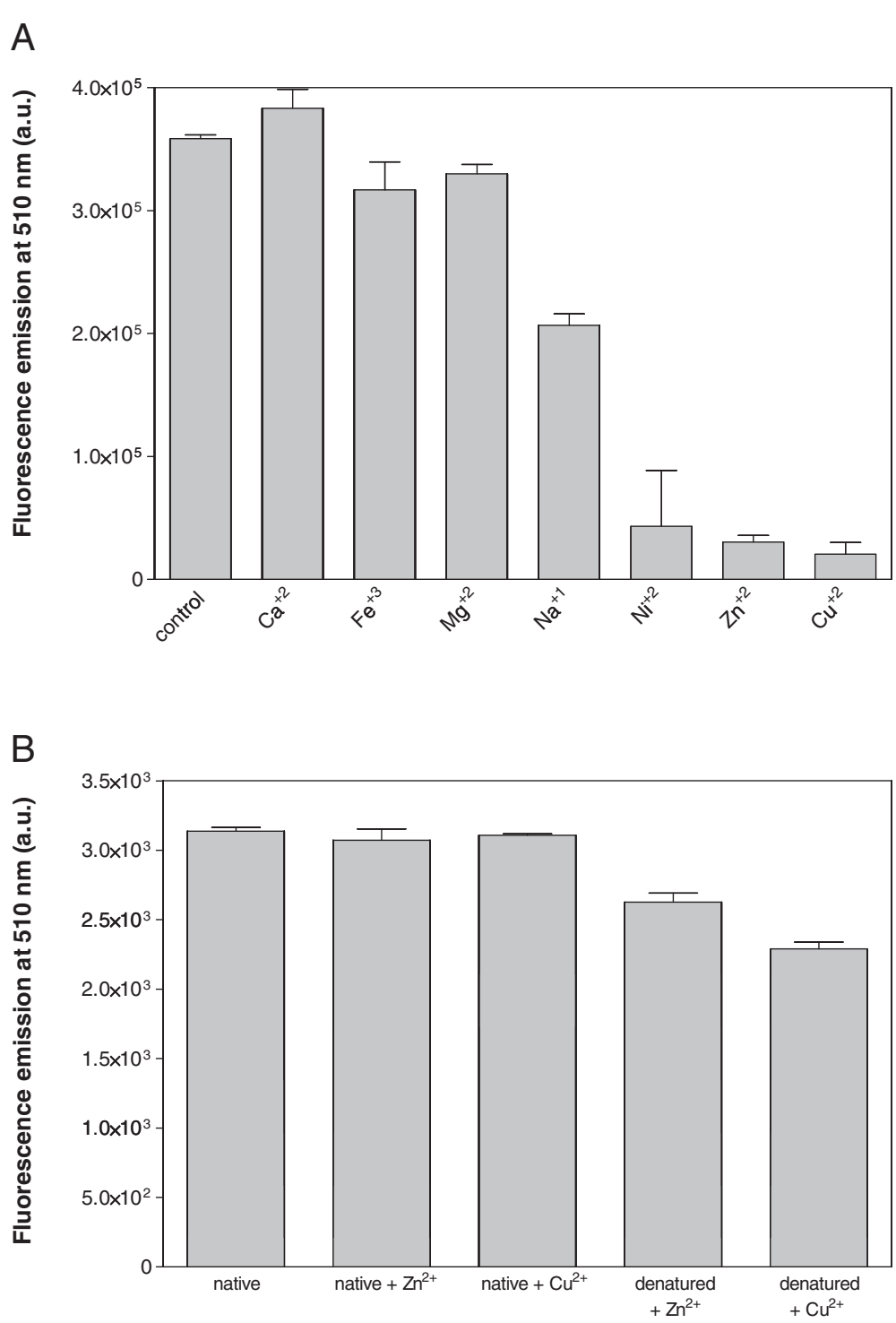

Figure 2 Fluorescence recovery in the presence of metallic ions. (A) Aß42wt-GFP IBs were denatured in $8 \mathrm{M}$ Gu. $\mathrm{HCl}$ for $4 \mathrm{~h}$ and diluted 100 fold in PBS (control) or in PBS containing different metallic ions at $25 \mu \mathrm{M}$ final concentration. (B) Purified untagged GFP and IBs were incubated in PBS in the absence (native) and presence of $8 \mathrm{M} \mathrm{Gu} \cdot \mathrm{HCl}$ for $4 \mathrm{~h}$ and diluted 100 -fold in PBS containing $\mathrm{Cu}^{+2}$ and $\mathrm{Zn}^{+2}$ at $25 \mu \mathrm{M}$ final concentration. In all cases, after incubation for $16 \mathrm{~h}$ fluorescence was recorded at $510 \mathrm{~nm}$. 
obtained with untagged GFP, for which denaturation with urea resulted in higher fluorescence recovery (Figure1B), suggesting that the used denaturant might affect the aggregation/refolding pathway. The proportion of fluorescent
GFP recovered after refolding was always higher than that in the original IB (Figure 1A). Aggregation usually corresponds to a second or higher order reaction and therefore, aggregation rates are extremely dependent

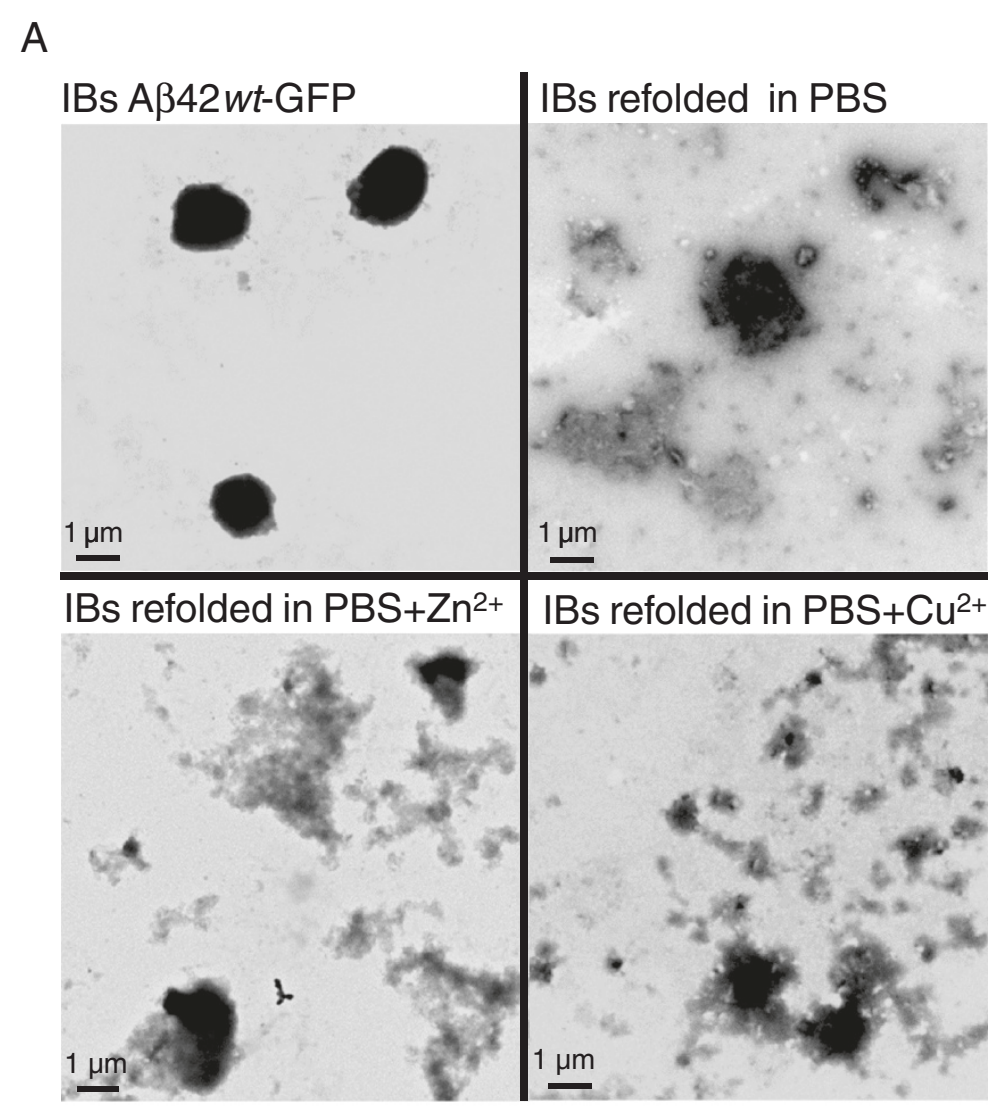

B

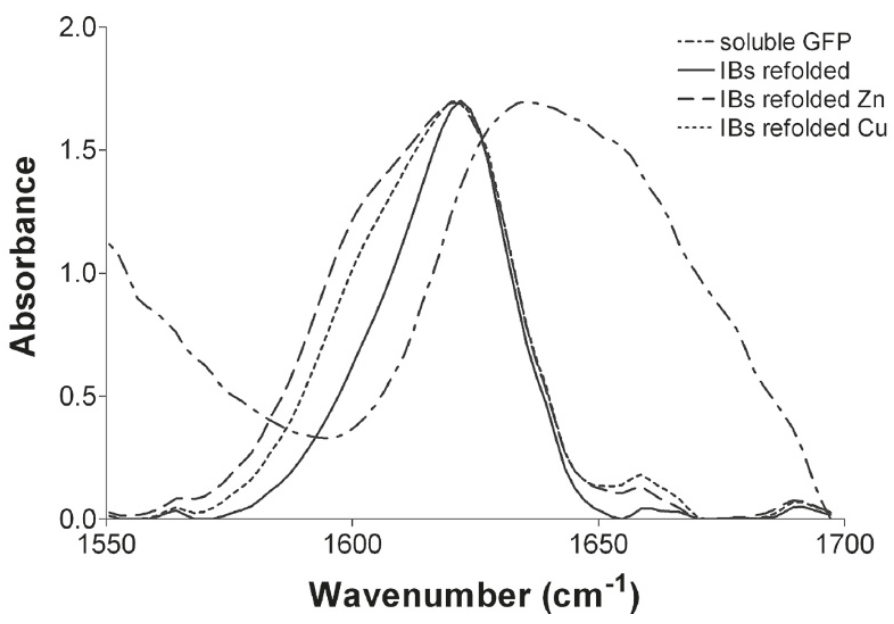

Figure 3 Morphology and secondary structure of aggregates. (A) Morphology of purified IBs and aggregates in refolding solutions in the absence and presence $\mathrm{Cu}^{+2}$ and $\mathrm{Zn}^{+2}$. (B) Analysis of the secondary structure of aggregates in refolding solutions in the absence and presence $\mathrm{Cu}^{+2}$ and $\mathrm{Zn}^{+2}$ by FT-IR spectroscopy in the amide I region of the spectra. The spectrum of native GFP is shown as a control. 
on protein concentrations [28]. Since the protein concentrations used during in vitro refolding are much lower than those existent in vivo, the folding of the GFP domain can compete more efficiently with the aggregation process, providing a larger dynamic response than in bacteria. However, the refolding efficiency of A $342-$ GFP IBs is about $\sim 10$-fold and $\sim 4$-fold lower than this of untagged GFP after denaturation in urea and $\mathrm{Gu} \cdot \mathrm{HCl}$, respectively, suggesting that, as it happens in vivo, the aggregation of the A 342 moiety competes the folding of GFP. Importantly, the activity recovery from the mutant IBs is higher than that from IBs formed by the wild-type sequence, supporting a kinetic competition between GFP folding and A 342 aggregation in vitro. The predicted lower aggregation rate of the mutant would account for the higher fluorescence recovery. By analogy, any agent that would increase the intrinsic aggregation rate of $A \beta 42$ will decrease the final amount of functional GFP and vice versa, allowing to screen for promoters or inhibitors of the protein aggregation process.

\section{Detection of the $A \beta 42$ aggregation-promoting effect of ionic metals}

Endogenous transition metals can bind amyloid peptides, like $\mathrm{A} \beta 42$, promoting their aggregation and the formation of amyloid fibers [29]. We analyzed if this pro-aggregating effect can be monitored using the above-described approach. Purified and $\mathrm{Gu} \cdot \mathrm{HCl}$ denatured A $\beta 42 w t$-GFP IBs were allowed to refold in PBS in the absence and in the presence of $\mathrm{Ca}^{2+}, \mathrm{Cu}^{2+}, \mathrm{Fe}^{3+}, \mathrm{Mg}^{2+}, \mathrm{Na}^{+}, \mathrm{Ni}^{2+}$ and $\mathrm{Zn}^{2+}$. $\mathrm{A}$ highly significant decrease of GFP activity was observed in the presence of the divalent cations $\mathrm{Cu}^{2+}, \mathrm{Ni}^{2+}$ and $\mathrm{Zn}^{2+}$ (Figure 2A). This result validates the method since there are strong evidences that zinc and copper enhance amyloid aggregation of $\mathrm{A} \beta 42$ and are a component of the senile plaques of Alzheimer's disease patients [30]. In the case of nickel, despite being a metal that lacks physiological relevance, it has also been described to bind A $\beta 42$ and enhance the peptide cytotoxicity, via nanoscale oligomer formation, with the same potency than $\mathrm{Cu}^{+2}$ [29]. Neither $\mathrm{Zn}^{+2}$ nor $\mathrm{Cu}^{+2}$ quenched the fluorescence of native untagged GFP (Figure 2B). Moreover, although the presence of $\mathrm{Zn}^{+2}$ and $\mathrm{Cu}^{+2}$ reduced untagged GFP fluorescence recovery, its effect was clearly lower than the one exerted on the refolding of A $342 w t$-GFP IBs (Figure 2B), indicating that in both cases the $A \beta 42$ peptide is a main player in the observed metal promoted aggregation. We analyzed the presence and morphology of aggregates in refolding solutions in the presence and absence of $\mathrm{Zn}^{+2}$ and $\mathrm{Cu}^{+2}$ by Transmission Electron Microscopy (Figure 3A). In contrast to intact IBs, which appear as electrodense spherical individual entities, all the aggregates in refolding solutions had an amorphous morphology. Nevertheless, Fourier Transformed Infrared Spectroscopy (FT-IR) analysis of the secondary structural features of the aggregated material shows that, in all the cases, the spectra in the amide I region is dominated by a band at $1620-1625 \mathrm{~cm}-1$, typically attributed to the presence of intermolecular $\beta$-sheet, which is accompanied by a minor band at $1690 \mathrm{~cm}-1$ corresponding to the splitting of the main $\beta$-sheet signal (Figure 3B). These two bands are considered a hallmark of the presence of amyloid-like contacts. The spectra of these aggregates are significantly different from that of native GFP, in which these signatures are absent (Figure 3B).

We explored if the approach allows visualizing a concentration dependent effect of $\mathrm{Zn}^{+2}$ and $\mathrm{Cu}^{+2}$ on the aggregation of the target at cation concentrations in the range of the physiological levels in human brain [31]. As shown in Figure 4, the approach is highly sensitive to metal concentrations. The titration curves indicate that the impact of $\mathrm{Cu}^{+2}$ on aggregation is somehow higher than that of $\mathrm{Zn}^{+2}$. Curve fitting to one site binding equation renders apparent dissociation constants of 0.6 and $1.9 \mu \mathrm{M}$ for copper and zinc, respectively. These data are in good agreement with early reports stating that, despite the two cations bind to equivalent sites in the $A \beta$ peptide, the dissociation constant for copper $(0.4 \mu \mathrm{M})$ is lower than that of zinc $(1.2 \mu \mathrm{M})$, as measured by fluorescence and H-NMR at $\mathrm{pH}$ 7.2 [32]. Interestingly, despite our assay is not intended for calculating dissociation constants, the ratio between the copper and zinc binding values is also $\sim 3$. Overall, the approach provides a fast qualitative assessment of metals effect on protein aggregation.

\section{Identification of inhibitors of metal-triggered $A \beta 42$ aggregation}

The identification of small molecules able to interfere protein aggregation is one of the approaches towards

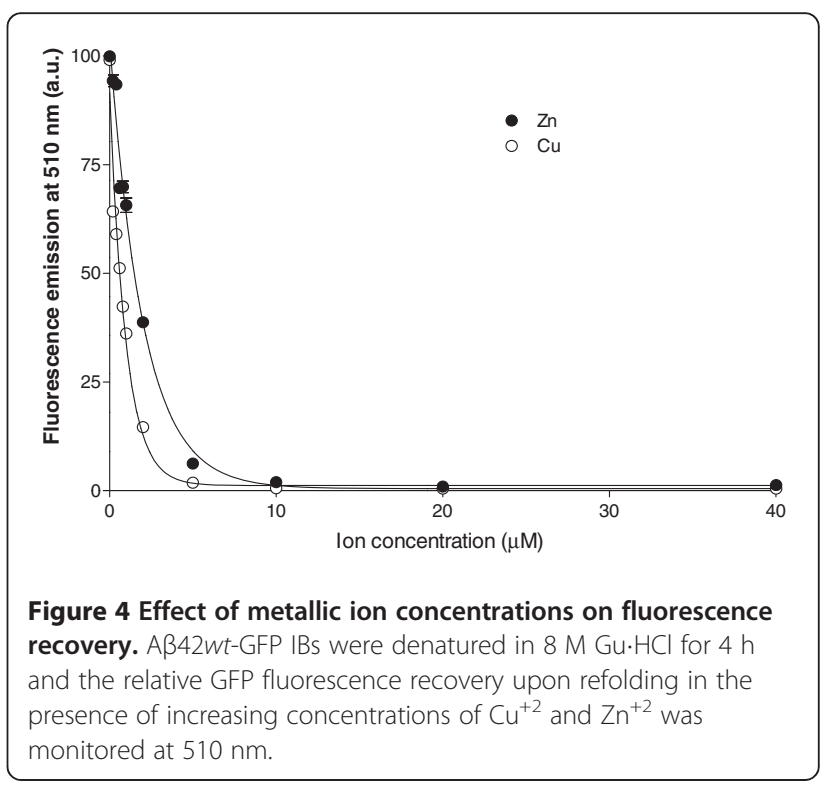


Table 1 Chemical structure of the small chemical compounds used in the present study

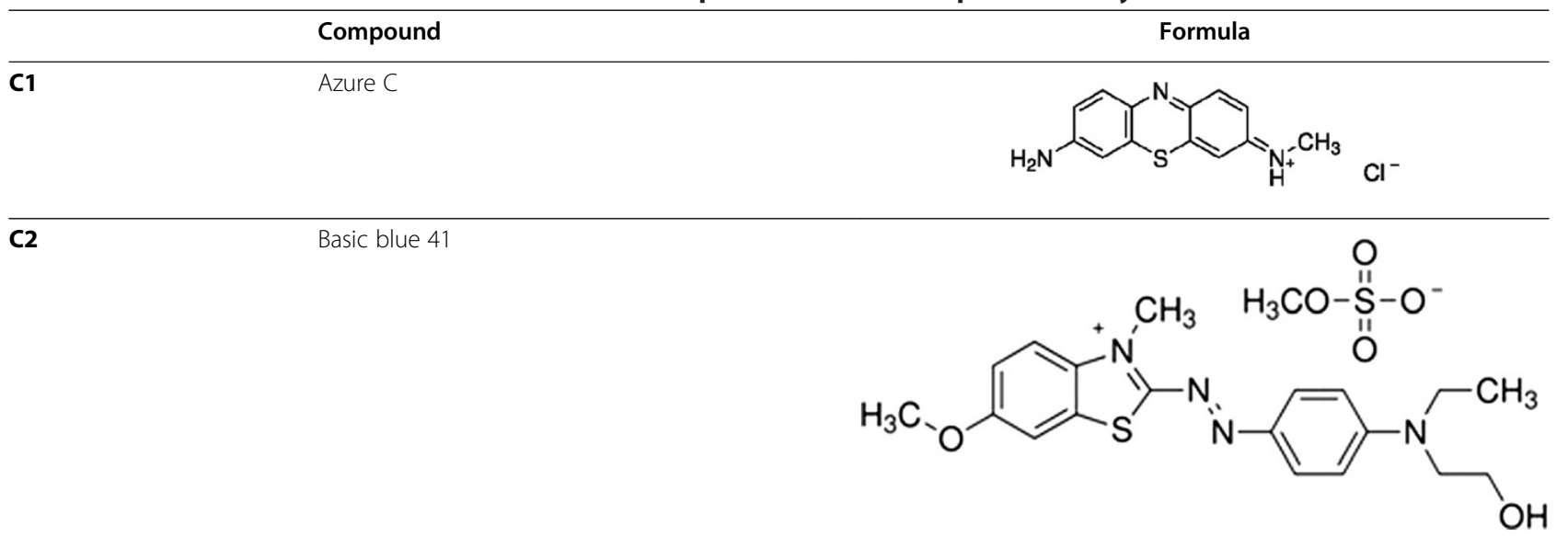

C3 Meclocycline sulfosalicylate

C4

C6 Quercetin

C7 Congo Red<smiles>Nc1c(N=Nc2ccc(-c3ccc(N=Nc4cc(S(=O)(=O)O)c5ccccc5c4N)cc3)cc2)cc(S(=O)(=O)O)c2ccccc12</smiles><smiles>Cc1ccc2c(c1)sc(-c1ccc(N(C)C)cc1)[n+]2C</smiles> 


C9 Apigenin

therapeutic treatment in amyloid disorders [30,31]. In principle, the outlined assay could be used to screen for such compounds. In particular, in the present work we focused in validating the approach for the identification of inhibitors of copper and zinc promoted aggregation. Despite divalent chelating molecules would work in vitro, we discarded the study of this type of molecules since in vivo they have shown to sequester cofactors that are essential for the cell physiology [32]. Instead, as a test case, the IBs refolding assay was performed in the presence of selected concentrations of a collection of small compounds that have been reported previously to bind synthetic amyloid $A \beta$ peptides or to modulate their aggregation and/or toxicity [33-37] but have never been assayed before in the presence of metals. The chemical formulae of the different compounds are shown in Table 1. Among the twelve tested compounds only meclocycline sulfosalicylate promoted a significant change in the final levels of GFP fluorescence in the presence of cooper (Figure 5A). This compound was also active in the presence of zinc but the strongest effect in the presence of this cation was observed for $o$-Vanillin (2Hydroxy-3-methoxybenzaldehyde) (Figure 5B). o-Vanillin has a cyclic structure that might quench GFP fluorescence. Effectively, the presence of $25 \mu \mathrm{M}$ concentration of the compound quenched $15 \%$ of the native untagged GFP fluorescence (Figure 5C). We monitored the effect of $o$-Vanillin on the refolding of A $342 w t$-GFP IBs in the absence of metals. The compound did not exhibit any positive effect on GFP recovery by itself and again a
$17 \%$ decrease in final fluorescence, mostly attributable to quenching, was observed. Overall, these data indicate that the presence of the compound reduces the metalpromoted aggregation effect by more than 15 fold, allowing to recover about $95 \%$ of the GFP-fluorescence observed in the absence of zinc and presence of $o$-Vanillin (Figure 5D). Interestingly, the $o$-Vanillin effect seems to be specific for zinc, with a negligibly effect for copper. This result is in agreement with previous data indicating that zinc and copper $A \beta 42$ induced aggregation pathways differ in the nature of their intermediate species and suggest that the natural product $o$-Vanillin targets specifically zinc promoted misfolding intermediates, which are characterized by a larger exposition of hydrophobic residues relative to those promoted by copper [38].

Although, to our knowledge, no in vivo effects of $o$-Vanillin on A $\beta 42$ promoted neuronal toxicity have been reported so far (work in progress). A closely related compound differing only in a $\mathrm{CH}_{2}$ group, 2Hydroxy-3-ethoxybenzaldehyde, completely blocked the neurotoxicity of the peptide to rat hippocampal neurons in culture [39], indicating that despite the simplicity of our assay, it may identify physiologically relevant hit compounds.

To obtain further insights on the effects of copper, zinc and $o$-Vanillin on A $\beta 42$ aggregation, we monitored the kinetics of GFP refolding after IBs denaturation in the presence and absence of these molecules by following the changes in fluorescence emission (Figure 5E). In PBS, GFP fluorescence was recovered following a 
double exponential curve with a rate constant of $0.90 \pm 0.02 \mathrm{~s}^{-1}$ and a half-life of $46.21 \mathrm{~min}$ for the fast reaction phase. The presence of both copper and zinc abrogated completely the fluorescence recovery already at the beginning of the refolding reaction, likely indicating that they promote a very fast aggregation of the fusion protein that totally competes the GFP domain folding reaction. The presence of $o$-Vanillin has a negligible effect on copper containing solutions. In contrast, this molecule allows recovery of $70 \%$ of the fluorescence at the end of the reaction in the presence of zinc. The rate constants and half-life for the fast phase were very close to those exhibited in the absence of metals, with values of $0.87 \pm 0.03 \mathrm{~s}^{-1}$ and $48.29 \mathrm{~min}$, respectively. This indicates that this compound acts interfering with zinc promoted A 342 aggregation without affecting GFP folding. Interestingly, the GFP fluorescence recovery reaction is completed after $3.5 \mathrm{~h}$, being thus a faster assay than those relying on the aggregation of synthetic peptides, which usually require at least overnight incubation [40]. We used the metallochromic Zincon reagent [41] to quantify the free levels of $\mathrm{Zn}^{2+}$ and $\mathrm{Cu}^{2+}$ in the absence and presence of $o$-Vanillin using spectrophotometry. No differences in free ion metal levels were observed (data not shown) suggesting that the compound does not act as a chelator but rather affects the refolding/aggregation kinetics of misfolded GFP fusions.

\section{Conclusions}

Based in our previous knowledge on the amyloid-like nature of the IBs formed by $A \beta$ peptides $[16,23]$ and the in vivo correlation between the aggregation rates and the total IBs activity $[22,26]$, we describe here a straightforward approach to identify compounds that modulate $A \beta$ aggregation using bacterial IBs. The method is implemented using 96 well plates and the

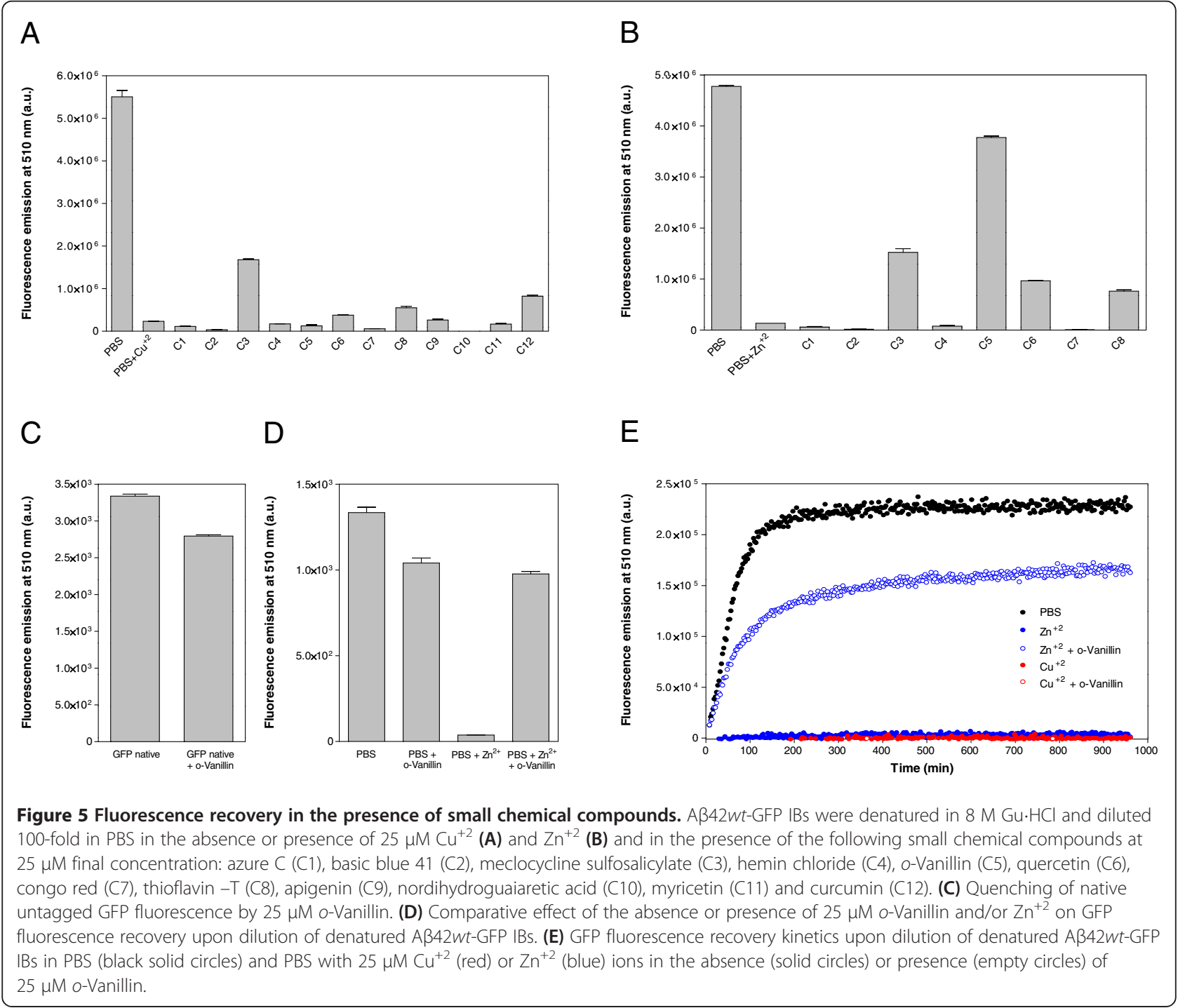


reaction takes less than four hours, making it suitable for high-throughput screening (Figure 6). Because most amyloid proteins and peptides form IBs when expressed in bacteria [17], the approach may have, in principle, a broad applicability in the search for aggregation modulators in conformational disorders. The assay does not require a detailed understanding of the structure of the aggregating species, and can provide an unbiased method for the discovery of hit compounds. IBs can be produced and purified in large amounts, making the method costeffective, especially when compared with the use of synthetic peptides. Despite its simplicity, the approach allows to distinguish between aggregation pathways and to identify inhibitors with therapeutic potential.

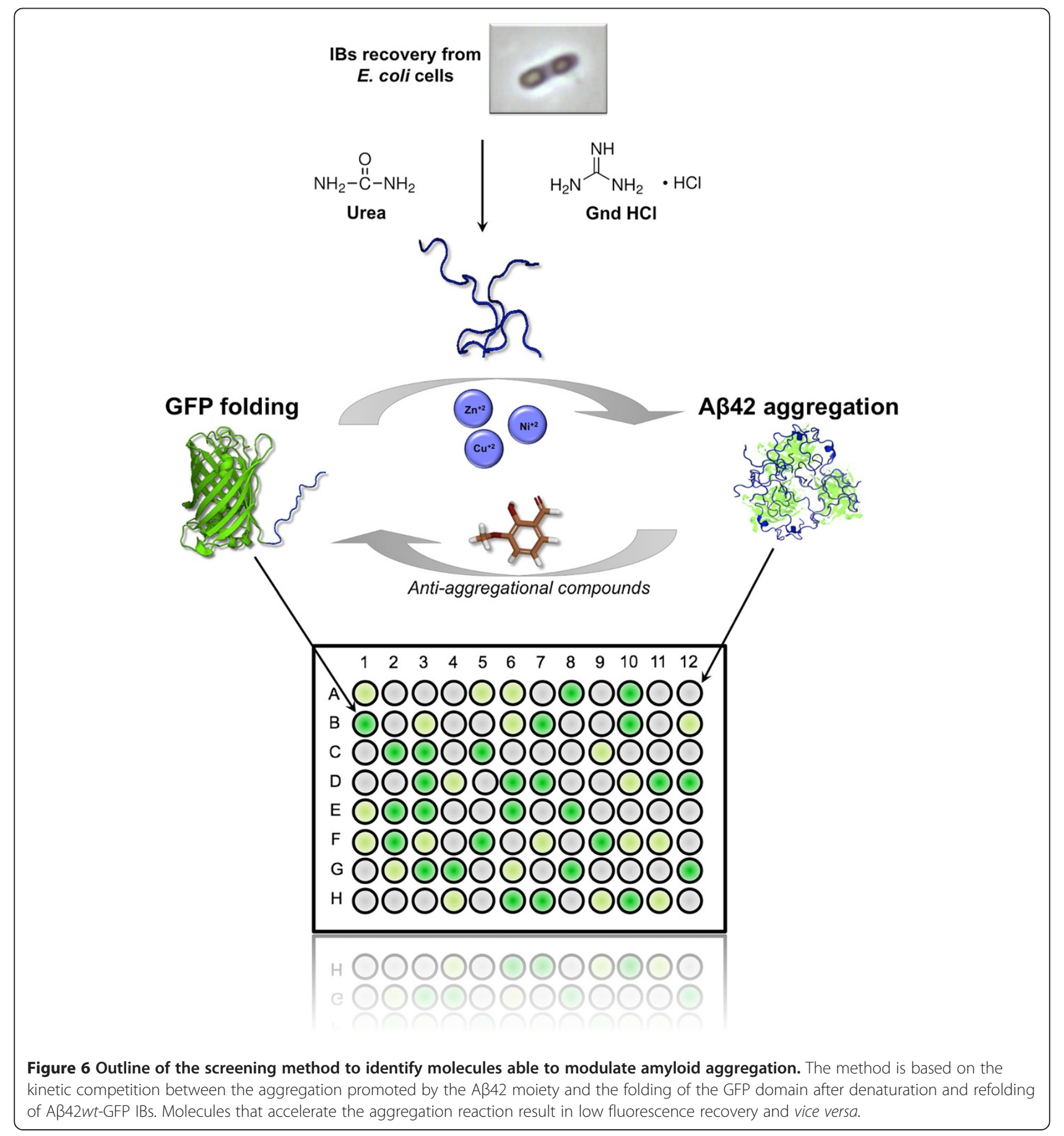




\section{Methods}

\section{Production and purification of inclusion bodies}

Escherichia coli BL21DE3 competent cells were transformed with pET28 vectors (Novagen, Inc., Madison, WI, USA) encoding the sequences for A $\beta 42 w t$-GFP fusion and the mutant A 442 F19D-GFP, as previously described [25].

$10 \mathrm{~mL}$ of bacterial cultures were grown at $37^{\circ} \mathrm{C}$ and $250 \mathrm{rpm}$ in LB medium containing $50 \mu \mathrm{g} / \mathrm{mL}$ of kanamycin. At an $\mathrm{OD}_{600}$ of $0.5,1 \mathrm{mM}$ of isopropyl$\beta$-D-1-thiogalactopyranoside (IPTG) was added to induce recombinant protein expression.

After 4 hours, cells were harvested by centrifugation and pellets were re-suspended in lysis buffer $(100 \mathrm{mM}$ $\mathrm{NaCl}, 1 \mathrm{mM}$ EDTA and $50 \mathrm{mM}$ Tris $\mathrm{pH}$ 8) to purify intracellular inclusion bodies (IBs), as previously described [41]. Briefly, protease inhibitor PMSF and lysozyme were added at the final concentrations of $15 \mathrm{mM}$ and $300 \mu \mathrm{g} / \mathrm{mL}$, respectively. After incubating at $37^{\circ} \mathrm{C}$ for $30 \mathrm{~min}$, detergent NP-40 was added at $1 \%$ and cells were incubated at $4^{\circ} \mathrm{C}$ for 50 min under mild agitation. To remove nucleic acids, cells were treated with DNase and RNase at $15 \mu \mathrm{g} / \mathrm{mL}$ at $37^{\circ} \mathrm{C}$ for $30 \mathrm{~min}$. IBs were collected by centrifugation at $12,000 \mathrm{xg}$ for $10 \mathrm{~min}$ and washed with lysis buffer containing $0.5 \%$ Triton X-100. Finally, they were washed three times with PBS to remove remaining detergent.

\section{In vitro refolding assay}

$15 \mu \mathrm{L}$ of purified IBs at $\mathrm{OD}_{360}=10$ were centrifuged for $10 \mathrm{~min}$ at $12000 \mathrm{xg}$. To denature the aggregates, the pellets were re-suspended in $10 \mu \mathrm{L}$ of $8 \mathrm{M} \mathrm{Gu} \cdot \mathrm{HCl}$ or $10 \mathrm{M}$ urea and incubated at room temperature for $4 \mathrm{~h}$. For the refolding process, denatured aggregates were dissolved in $990 \mu \mathrm{L}$ of refolding buffer. These buffers were based on PBS, previously treated with Chelex 100 chelating resin from Sigma-Aldrich (St. Louis, MO, USA), and the following salts and compounds according to the different refolding assays: $\mathrm{CaCl}_{2}, \mathrm{FeCl}_{3}, \mathrm{MgCl}_{2}, \mathrm{NaCl}, \mathrm{NiCl}_{2}$, $\mathrm{ZnCl}_{2}, \mathrm{CuCl}_{2}$, apigenin, azure $\mathrm{C}$, basic blue 41, congo red, curcumin, hemin chloride, meclocycline sulfosalicylate, myricetin, nordihydroguaiaretic acid, $o$-Vanillin (2-hydroxy-3-methoxybenzaldehyde), thioflavin - $\mathrm{T}$ and quercetin, all obtained from Sigma-Aldrich (St. Louis, MO, USA). Equimolar concentrations of purified untagged GFP were used in control experiments. GFP fluorescence of the solutions containing refolded IBs or untagged GFP were measured in a 96 well plate in a Victor 3 Plate Reader (Perkin-Elmer, Inc., Waltham, MA, USA) using excitation and emission wavelength filters of $405 \mathrm{~nm}$ and $510 \mathrm{~nm}$, respectively or in a Jasco FP-8200 spectrofluorometer using excitation and emission wavelengths of $480 \mathrm{~nm}$ and $510 \mathrm{~nm}$, respectively. Measurements were performed in triplicate. For kinetic experiments, the refolding step was followed using the same parameters and reading the fluorescence emission every $2 \mathrm{~min}$ for $16 \mathrm{~h}$. In order to homogenize the samples, these were briefly shacked (for 5 s) before each determination.

\section{Transmission electronic microscopy}

IBs or aggregates containing solutions were placed on carbon-coated copper grids, and left to stand for five minutes. The grids were washed with distilled water and stained with $2 \%(\mathrm{w} / \mathrm{v})$ uranyl acetate for another two minutes before analysis using a HitachiH-7000 transmission electron microscope (Hitachi, Tokyo, Japan) operating at accelerating voltage of $75 \mathrm{kV}$.

\section{Secondary structure determination}

Aggregates present in refolding solutions were precipitated by centrifugation at $12.000 \mathrm{xg}$ (g en cursiva i sense espais) for $30 \mathrm{~min}$, resuspended in Milli-Q water and analyzed, together with purified untagged GFP, by FT-IR spectroscopy using a Bruker Tensor 27 FT-IR Spectrometer (Bruker Optics Inc) with a Golden Gate MKII ATR accessory. Each spectrum consists of 16 independent scans, measured at a spectral resolution of $2 \mathrm{~cm}^{-1}$ within the $1700-1500 \mathrm{~cm}^{-1}$ range. All spectral data were acquired and normalized using the OPUS MIR Tensor 27 software.

\section{Competing interests}

The authors declare that they have no competing interests.

\section{Acknowledgements}

This work was supported by grants BFU2010-14901 from Ministerio de Ciencia e Innovación (Spain) and 2009-SGR 760 from AGAUR (Generalitat de Catalunya). RS is recipient of a contract from the Ramón y Cajal Programme from Ministerio de Ciencia e Innovación. NSG is recipient of a FEBS longterm fellowship. SV has been granted an ICREA ACADEMIA award (ICREA).

\section{Author details}

${ }^{1}$ Departament de Bioquímica i Biologia Molecular, Facultat de Biociències, Universitat Autònoma de Barcelona, E-08193, Bellaterra, Spain. ${ }^{2}$ Institut de Biotecnologia i de Biomedicina, Universitat Autònoma de Barcelona, E-08193, Bellaterra, Spain. ${ }^{3}$ Present address: Departament de Fisicoquímica, Facultat de Farmàcia, Universitat de Barcelona, Avda. Joan XXIII, 08028, Barcelona, Spain. ${ }^{4}$ Present address: Medical Research Council Laboratory of Molecular Biology, Hills Road, Cambridge, CB2 OQH, United Kingdom.

\section{Authors' contributions}

SV supervised the project, designed the study and drafted the manuscript. AVP and AE carried out all experiments and drafted the manuscript. RS and NSG critically revised and corrected the manuscript. All authors read and approved the final manuscript.

Received: 21 January 2012 Accepted: 3 May 2012

Published: 3 May 2012

\section{References}

1. Chiti F, Dobson CM: Protein misfolding, functional amyloid, and human disease. Annu Rev Biochem 2006, 75:333-366.

2. Fernandez-Busquets $X$, de Groot NS, Fernandez D, Ventura S: Recent structural and computational insights into conformational diseases. Curr Med Chem 2008, 15(13):1336-1349.

3. Friedman R: Aggregation of amyloids in a cellular context: modelling and experiment. Biochem J 2011, 438(3):415-426. 
4. Ross CA, Poirier MA: Protein aggregation and neurodegenerative disease. Nat Med 2004, 10(Suppl):S10-S17.

5. Lee LL, Ha H, Chang YT, DeLisa MP: Discovery of amyloid-beta aggregation inhibito'rs using an engineered assay for intracellular protein folding and solubility. Protein Sci 2009, 18(2):277-286.

6. Morell M, de Groot NS, Vendrell J, Aviles FX, Ventura S: Linking amyloid protein aggregation and yeast survival. Mol Biosyst 2011, 7(4):1121-1128.

7. Amijee H, Madine J, Middleton DA, Doig AJ: Inhibitors of protein aggregation and toxicity. Biochem Soc Trans 2009, 37(Pt 4):692-696.

8. Hardy J, Selkoe DJ: The amyloid hypothesis of Alzheimer's disease: progress and problems on the road to therapeutics. Science 2002, 297 (5580):353-356.

9. Kuperstein I, Broersen K, Benilova I, Rozenski J, Jonckheere W, Debulpaep M, Vandersteen A, Segers-Nolten I, Van Der Werf K, Subramaniam V, et al: Neurotoxicity of Alzheimer's disease Abeta peptides is induced by small changes in the Abeta42 to Abeta40 ratio. EMBO J 2010, 29(19):3408-3420.

10. Karran E, Mercken M, De Strooper B: The amyloid cascade hypothesis for Alzheimer's disease: an appraisal for the development of therapeutics. Nat Rev Drug Discov 2011, 10(9):698-712.

11. Bonda DJ, Lee HG, Blair JA, Zhu X, Perry G, Smith MA: Role of metal dyshomeostasis in Alzheimer's disease. Metallomics 2011, 3(3):267-270.

12. Jomova K, Vondrakova D, Lawson M, Valko M: Metals, oxidative stress and neurodegenerative disorders. Mol Cell Biochem 2010, 345(1-2):91-104.

13. de Groot NS, Espargaro A, Morell M, Ventura S: Studies on bacterial inclusion bodies. Future Microbiol 2008, 3:423-435

14. Ventura S, Villaverde A: Protein quality in bacterial inclusion bodies. Trends Biotechnol 2006, 24(4):179-185.

15. Carrio M, Gonzalez-Montalban N, Vera A, Villaverde A, Ventura S: Amyloidlike properties of bacterial inclusion bodies. J Mol Biol 2005, 347(5):1025-1037.

16. Morell M, Bravo R, Espargaro A, Sisquella X, Aviles FX, Fernandez-Busquets X, Ventura S: Inclusion bodies: specificity in their aggregation process and amyloid-like structure. Biochim Biophys Acta 2008, 1783(10):1815-1825.

17. de Groot NS, Sabate R, Ventura S: Amyloids in bacterial inclusion bodies. Trends Biochem Sci 2009, 34(8):408-416.

18. Wang L, Maji SK, Sawaya MR, Eisenberg D, Riek R: Bacterial inclusion bodies contain amyloid-like structure. PLoS Biol 2008, 6(8):e195.

19. Sabate $R$, de Groot NS, Ventura S: Protein folding and aggregation in bacteria. Cell Mol Life Sci 2010, 67(16):2695-2715.

20. Garcia-Fruitos E, Sabate R, de Groot NS, Villaverde A, Ventura S: Biological role of bacterial inclusion bodies: a model for amyloid aggregation. FEBS J 2011, 278(14):2419-2427.

21. Lotti M: Bacterial inclusion bodies as active and dynamic protein ensembles. FEBS J 2011, 278(14):2407.

22. Villar-Pique A, de Groot NS, Sabate R, Acebron SP, Celaya G, FernandezBusquets X, Muga A, Ventura S: The Effect of Amyloidogenic Peptides on Bacterial Aging Correlates with Their Intrinsic Aggregation Propensity. J Mol Biol 2011. doi:http://dx.doi.org/10.1016/j.jmb.2011.12.014.

23. Dasari M, Espargaro A, Sabate R, Lopez Del Amo JM, Fink U, Grelle G, Bieschke J, Ventura S, Reif B: Bacterial Inclusion Bodies of Alzheimer's Disease betaAmyloid Peptides Can Be Employed To Study Native-Like Aggregation Intermediate States. Chem Bio Chem 2011, 12(3):407-423.

24. Garcia-Fruitos E, Gonzalez-Montalban N, Morell M, Vera A, Ferraz RM, Aris A, Ventura S, Villaverde A: Aggregation as bacterial inclusion bodies does not imply inactivation of enzymes and fluorescent proteins. Microb Cell Fact 2005, 4:27.

25. de Groot NS, Aviles FX, Vendrell J, Ventura S: Mutagenesis of the central hydrophobic cluster in Abeta42 Alzheimer's peptide, Side-chain properties correlate with aggregation propensities. FEBS J 2006, 273(3):658-668.

26. de Groot NS, Ventura S: Protein activity in bacterial inclusion bodies correlates with predicted aggregation rates. J Biotechnol 2006, 125(1):110-113.

27. de Groot NS, Ventura S: Effect of temperature on protein quality in bacterial inclusion bodies. FEBS Lett 2006, 580:6471-6476.

28. Kiefhaber $\mathrm{T}$, Rudolph $\mathrm{R}$, Kohler $\mathrm{HH}$, Buchner J: Protein aggregation in vitro and in vivo: a quantitative model of the kinetic competition between folding and aggregation. Bio/Technology 1991, 9(9):825-829.

29. Jin L, Wu WH, Li QY, Zhao YF, Li YM: Copper inducing Abeta42 rather than Abeta40 nanoscale oligomer formation is the key process for Abeta neurotoxicity. Nanoscale 2011, 3(11):4746-4751.
30. Zhang $X$, Smith DL, Meriin AB, Engemann S, Russel DE, Roark M, Washington SL, Maxwell MM, Marsh JL, Thompson LM, et al: A potent small molecule inhibits polyglutamine aggregation in Huntington's disease neurons and suppresses neurodegeneration in vivo. Proc Natl Acad Sci U S A 2005, 102(3):892-897.

31. Chen J, Armstrong AH, Koehler AN, Hecht MH: Small molecule microarrays enable the discovery of compounds that bind the Alzheimer's Abeta peptide and reduce its cytotoxicity. J Am Chem Soc 2010,

132(47):17015-17022

32. Hegde ML, Bharathi $P$, Suram A, Venugopal $C$, Jagannathan $R$, Poddar $P$, Srinivas P, Sambamurti K, Rao KJ, Scancar J, et al: Challenges associated with metal chelation therapy in Alzheimer's disease. J Alzheimer's Dis 2009, 17(3):457-468.

33. Necula M, Kayed R, Milton S, Glabe CG: Small molecule inhibitors of aggregation indicate that amyloid beta oligomerization and fibrillization pathways are independent and distinct. J Biol Chem 2007 282(14):10311-10324.

34. Necula M, Breydo L, Milton S, Kayed R, van der Veer WE, Tone P, Glabe CG: Methylene blue inhibits amyloid Abeta oligomerization by promoting fibrillization. Biochemistry 2007, 46(30):8850-8860.

35. Kim H, Park BS, Lee KG, Choi CY, Jang SS, Kim YH, Lee SE: Effects of naturally occurring compounds on fibril formation and oxidative stress of beta-amyloid. J Agric Food Chem 2005, 53(22):8537-8541.

36. Jagota S, Rajadas J: Effect of Phenolic Compounds Against Abeta Aggregation and Abeta-Induced Toxicity in Transgenic C. elegans. Neurochem Res 2012, 37(1):40-48.

37. Matsuzaki K, Noguch T, Wakabayashi M, Ikeda K, Okada T, Ohashi Y, Hoshino M, Naiki $\mathrm{H}$ : Inhibitors of amyloid beta-protein aggregation mediated by GM1containing raft-like membranes. Biochim Biophys Acta 2007, 1768(1):122-130.

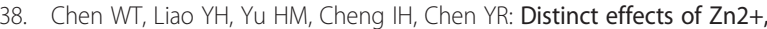
$\mathrm{Cu} 2+, \mathrm{Fe} 3+$, and $\mathrm{Al} 3+$ on amyloid-beta stability, oligomerization, and aggregation: amyloid-beta destabilization promotes annular protofibril formation. J Bio/ Chem 2011, 286(11):9646-9656.

39. De Felice FG, Vieira MN, Saraiva LM, Figueroa-Villar JD, Garcia-Abreu J, Liu R, Chang L, Klein WL, Ferreira ST: Targeting the neurotoxic species in Alzheimer's disease: inhibitors of Abeta oligomerization. FASEB J 2004, 18(12):1366-1372.

40. Rodriguez-Rodriguez C, Sanchez De Groot N, Rimola A, Alvarez-Larena A, Lloveras V, Vidal-Gancedo J, Ventura S, Vendrell J, Sodupe M, Gonzalez Duarte P: Design, selection, and characterization of thioflavin-based intercalation compounds with metal chelating properties for application in Alzheimer's disease. J Am Chem Soc 2009, 131(4):1436-1451.

41. Hilario E, Romero I, Celis H: Determination of the physicochemical constants and spectrophotometric characteristics of the metallochromic Zincon and its potential use in biological systems. J Biochem Biophys Methods 1990, 21(3):197-207.

\section{doi:10.1186/1475-2859-11-55}

Cite this article as: Villar-Piqué et al.: Using bacterial inclusion bodies to screen for amyloid aggregation inhibitors. Microbial Cell Factories 2012 11:55.

\section{Submit your next manuscript to BioMed Central and take full advantage of:}

- Convenient online submission

- Thorough peer review

- No space constraints or color figure charges

- Immediate publication on acceptance

- Inclusion in PubMed, CAS, Scopus and Google Scholar

- Research which is freely available for redistribution 